\title{
Uma análise do efeito dos gastos públicos em educação sobre a criminalidade no Brasil *
}

\author{
Kalinca Léia Becker * \\ Ana Lúcia Kassouf ****
}

\begin{abstract}
Resumo
O objetivo do estudo é analisar se o gasto público em educação pode contribuir para reduzir a taxa de homicídios e se é necessário um período para que esse resultado seja observado. Para isso, foram utilizados dados socioeconômicos dos estados brasileiros e um modelo de painel dinâmico (GMM-SYS) com uma defasagem para os gastos com educação por habitante, além da relação contemporânea. Os resultados indicaram uma elasticidade negativa de aproximadamente 0,1 na primeira defasagem, ou seja, se os gastos com educação aumentarem $10 \%$, a taxa de homicídios diminuiria $1 \%$ no período seguinte, evidenciando que investir em educação pode ser uma forma de política pública de longo prazo para reduzir a criminalidade.
\end{abstract}

Palavras chave: Crime; Economia do crime; Educação; Gastos públicos; GMM em Sistema.

\begin{abstract}
An analysis of the effect of public education expenditure on criminality in Brazil

This study aims to analyze whether public spending on education can contribute to reducing the homicide rate and whether it is necessary to observe this result over a period of time. In this sense, socioeconomic data from the Brazilian states and a dynamic panel model (GMM-SYS) were used to highlight the difference in education expenditures per capita, in addition to the contemporary relationship. The results indicated a negative elasticity of approximately 0.1 in the first lag, that is, if education spending increased by $10 \%$, the homicide rate would decrease by $1 \%$ in the following period, highlighting that investment in education could be a form of long-term public policy to reduce crime.
\end{abstract}

Keywords: Crime; Economics of crime; Education; Public spending; GMM System.

JEL K14, I25, C23.

\section{Introdução}

A criminalidade é um problema social que afeta negativamente a qualidade de vida dos cidadãos, gerando custos econômicos e grandes perdas, principalmente, à vida humana. A maior parte das vítimas da violência são pessoas em idade economicamente ativa. Segundo os dados do Sistema Único de Saúde, no ano de

\footnotetext{
* Artigo recebido em 25 de agosto de 2014 e aprovado em 15 de fevereiro de 2017.

** Professora da Universidade Federal de Santa Maria (UFSM), Santa Maria, RS. E-mail: kalincabecker@gmail.com.

${ }^{* * *}$ Professora Titular da Escola Superior de Agricultura Luiz de Queiroz da Universidade de São Paulo (Esalq), Piracicaba, SP. E-mail: anakassouf@usp.br.
} 
2010, aproximadamente 59\% dos homicídios ocorreram com pessoas em idade entre 20 e 39 anos.

Do ponto de vista econômico, isso representa custos substanciais em termos de perda de capital humano e, consequentemente, da capacidade produtiva, pois estas pessoas poderiam contribuir para o crescimento do PIB nacional durante um longo período. Carvalho et al. (2007) estimaram que a perda de produção no Brasil devido aos homicídios foi de R\$ 9,1 bilhões em 2001. Cerqueira e Soares (2016) estimaram que o custo dos homicídios sobre o bem-estar corresponde a cerca de 2,3\% do fluxo anual do PIB brasileiro. Esse cenário tem levado a sociedade e o governo a refletir sobre as principais causas da criminalidade e também gera uma demanda crescente por políticas públicas para o combate do problema.

A literatura econômica, geralmente, busca explicar as taxas de criminalidade através da análise de como a probabilidade individual de cometer um crime é afetada pelas expectativas de custo e benefício da atividade ilegal. No modelo tradicional do crime, desenvolvido por Becker (1968), os indivíduos agem segundo a motivação econômica, ou seja, decidem cometer crimes se houver possibilidade de retorno financeiro.

Nesse modelo, a educação é uma medida das habilidades do indivíduo na sua atividade produtiva, seja ela criminosa ou não. Os canais pelos quais a educação pode afetar as decisões individuais subsequentes de ingresso nas atividades ilícitas foram organizados em quatro pontos descritos a seguir.

Primeiro, a escolaridade altera o custo de oportunidade da atividade criminosa, pois um indivíduo mais educado obtém melhores oportunidades de salário e emprego, que aumenta o custo de cometer um crime. Além disso, a punição pode ser mais custosa para indivíduos mais educados, já que o encarceramento implica em tempo fora do mercado de trabalho (Becker, 1968).

Segundo, a educação pode alterar as taxas individuais de preferência no tempo ou de aversão ao risco. Becker e Mulligan (1997) mostraram que a escolaridade pode aumentar a paciência dos indivíduos. Arrow (1997) mostrou ainda que a escolaridade afeta diretamente os custos psíquicos de desobedecer às leis. Logo, indivíduos mais pacientes e mais avessos ao risco provavelmente irão considerar as punições do crime mais custosas.

Terceiro, é possível que a probabilidade de cometer um crime hoje dependa do montante de crime cometido no passado, pois, assim como nas atividades legais, os criminosos adquirem experiência ao longo do tempo, implicando em ganhos de produtividade, o que funcionaria como uma espécie de learning-by-doing da atividade criminal. Lochner e Moretti (2009) sugerem que frequentar a escola mantém os indivíduos ocupados e fora das ruas, o que diminui a possibilidade de ingresso precoce em atividades ilícitas. Dessa forma, a frequência escolar pode ter um efeito de longo prazo sobre a taxa de participação na atividade criminal. 
Quarto, é possível ainda que a probabilidade de um indivíduo ingressar na atividade criminosa dependa da taxa de participação dos seus pares nessa atividade. Se a escola for capaz de fornecer bons exemplos de conduta aos seus frequentadores, interagir nesse ambiente pode influenciar o processo de tomada de decisão e reduzir a probabilidade de cometer uma atividade ilícita (Lochner, 2010).

Estes canais sugerem que o aumento da frequência escolar pode reduzir a probabilidade subsequente de ingresso no crime. É importante destacar também que a teoria evidencia que a escolaridade pode aumentar retornos marginais do crime, uma vez que aumenta a eficiência da execução e planejamento (Becker, 1968; Lochner, 2004; Soares, 2004; Carneiro et al., 2005). Porém, a literatura que busca analisar os fatores determinantes da criminalidade no Brasil, geralmente, observa um efeito líquido negativo entre a educação e o crime.

Fajnzlber e Araújo Jr. (2001) analisaram alguns determinantes econômicos e demográficos do crime e obtiveram uma elasticidade positiva entre analfabetismo e as taxas de homicídios, ou seja, maior educação (menor taxa de analfabetismo) resulta em menos crime. Kume (2004) e Santos (2009) obtiveram uma elasticidade negativa entre uma medida de escolaridade média ${ }^{1}$ e a taxa de crimes letais. Resende e Viegas (2011) utilizam como medida de educação o percentual de adolescentes entre 15 e 17 anos na escola e observa uma relação negativa com a taxa de homicídios. No mesmo sentido, Scorzafave e Soares (2009) observaram uma relação negativa de 1,7 entre a taxa de matrículas e crimes não pecuniários. Carneiro et al. (2005) utilizaram informações dos prisioneiros do Presídio da Papuda em Brasília e observaram que, quanto maior a escolaridade, menor a probabilidade de o indivíduo cometer homicídio. Chioda et al. (2015) analisaram o efeito do programa Bolsa Família sobre o crime e verificaram que a expansão do programa, associada a frequência escolar de adolescentes em situação de vulnerabilidade socioeconômica com idade entre 16 e 17 anos, contribuiu para a diminuição dos homicídios na cidade de São Paulo.

As premissas da literatura teórica, somadas as evidências da literatura empírica, indicam que a educação da população pode contribuir para reduzir o crime. Dessa forma, a alocação de recursos na educação pode ser uma forma de política pública de longo prazo para a redução da criminalidade.

Uma das preocupações da literatura sobre políticas na área de educação é avaliar qual a melhor forma de realizar os investimentos. Cunha et al. (2006) evidenciaram que a educação de um indivíduo é resultado de um processo de acúmulo de capital humano que ocorre ao longo do ciclo de vida e envolve investimento e alocação do tempo. Os investimentos nos períodos iniciais do ciclo

(1) Kume (2004) utiliza como medida de educação o número médio de anos de estudo para população a partir dos 25 anos, já Santos (2009) utiliza a escolaridade média, em anos de estudo, dos homens entre 15 e 30 anos de idade. 
de vida propiciam o desenvolvimento de habilidades que potencializam a acumulação de capital humano nos períodos subsequentes e promovem melhores oportunidades para o indivíduo no mercado de trabalho, tornando-o menos propenso a cometer crimes.

Dessa forma, é possível que os resultados do investimento em educação sobre as taxas de criminalidade não sejam observados imediatamente, uma vez que é necessário um período para que as pessoas frequentem os cursos de formação educacional. Durante esse período, as pessoas desenvolvem habilidades que aumentam a produtividade, o que lhes possibilitará encontrar melhores oportunidades no mercado de trabalho, com maiores salários. No caso da educação de crianças e jovens, o tempo de frequência escolar e a interação nesse ambiente permitem a absorção das noções de moralidade, civilidade e de obediência as leis que, normalmente, integram as regras de convivência no espaço escolar e podem funcionar como um mecanismo informal de controle do comportamento dos indivíduos e de prevenção ao engajamento em atividades ilícitas (Lochner, 2011; Heckman, 2013).

O retorno social da educação somado ao elevado custo social do crime torna a atuação pública nessa área economicamente importante. Nesse estudo, procuramos contribuir com a literatura já existente ao analisar se o gasto público com educação pode contribuir para reduzir a taxa de homicídios e se é necessário um período para que esse resultado seja observado. As estimativas foram realizadas através da metodologia GMM-SYS, com dados em painel dos estados brasileiros nos anos de 2001 a 2009, que permite introduzir, além da relação contemporânea, o efeito defasado dos gastos públicos em educação sobre a taxa de homicídios. Diferentemente dos demais estudos que utilizam como medida de educação o acesso à escola ou a escolaridade da população, utilizamos os gastos públicos na área como medida e, assim, buscamos identificar se a atuação pública na área de educação pode ser utilizada como uma forma de política de prevenção do crime.

\section{Literatura teórica e empírica}

Em economia, a maioria das pesquisas que tentam explicar a criminalidade baseia-se no modelo teórico proposto por Becker (1968), que tem como ponto de partida um modelo de escolha racional em que o indivíduo irá cometer crimes se o benefício esperado do crime for maior que o custo de execução do mesmo.

Para tomar sua decisão, o indivíduo analisa questões como: o custo oportunidade, o custo moral, o custo de execução e planejamento do crime, o custo associado à punição e sua respectiva probabilidade de ocorrer, entre outros. É de se esperar ainda que, assim como nas atividades legais, os criminosos adquiram experiência ao longo do tempo, implicando em ganhos de produtividade, o que funcionaria como uma espécie de learning-by-doing da atividade criminal. 
Essa aprendizagem e especialização na atividade criminosa, que ocorre ao longo do tempo, pode ocasionar a transferência do crime de um período para outro, denominado de "efeito inércia" do crime. A existência desse efeito é observada em muitos estudos da literatura nacional e os coeficientes estimados variam entre $0,4 \mathrm{e}$ 0,8, dependendo dos dados e da metodologia utilizada (Andrade; Lisboa, 2000; Kume, 2004; Almeida et al. 2005; Santos, 2009; Sachsida et al. 2010).

A literatura baseada no modelo econômico do crime reconhece que a educação pode ter uma relação positiva ou negativa com a criminalidade. A relação positiva ocorre em função do custo de planejamento, já que, quanto maior o nível de escolaridade, maior será a eficiência do indivíduo na execução e planejamento do crime e, portanto, menor será o custo. Além disso, em termos agregados, uma região com maior escolaridade média, geralmente, apresenta maior renda per capita, tornando-se economicamente mais atrativa para a atuação do crime (Araújo Jr.; Fajnzylber, 2001).

Porém, de maneira geral, as evidências empíricas apresentam um efeito líquido negativo, ou seja, a educação reduz a criminalidade. A relação positiva está geralmente associada a alguns tipos de crime contra a propriedade (Lochner, 2004; Soares, 2004; Carneiro et al., 2005). Mesmo assim, o estudo de Kling (2002), utilizando dados criminais da Califórnia nos Estados Unidos, mostrou que o estigma de uma condenação criminal é bastante elevado entre os criminosos de colarinho branco, o que implica que custo do crime para indivíduos educados pode ser elevado mesmo nos crimes contra a propriedade. Entretanto, é evidente que isso ocorre apenas se as instituições criminais forem fortes e a condenação for efetivada.

A relação negativa entre a educação e a atividade criminosa ocorre em função do custo de oportunidade, pois um indivíduo mais educado, com melhores oportunidades no mercado de trabalho, tem um custo de oportunidade maior, o que aumenta o custo de cometer um crime. Além disso, no caso de uma eventual prisão, o tempo fora do mercado de trabalho pode ser mais custoso para indivíduos mais educados.

Conforme evidenciado por Cunha et al. (2006), o nível educacional de um indivíduo é resultado de um processo de acúmulo de capital humano que ocorre ao longo do ciclo de vida. Sendo assim, a escolaridade pode ter efeitos a longo prazo sobre o comportamento criminoso. (Becker; Mulligan, 1997; Lochner, 2011; Chioda, 2015).

Lochner (2004) desenvolveu um modelo de escolha ótima onde o indivíduo aloca cada período de tempo $t$ para investir em capital humano $\left(I_{t}\right)$, no mercado de trabalho ou na atividade criminosa $\left(k_{t}\right)$, com o objetivo de maximizar a expectativa de ganho ao longo da vida. Se o indivíduo entra no crime, ele enfrenta uma probabilidade de encarceramento. Se isso acontecer, supõe-se que o indivíduo não poderá investir em capital humano, trabalhar ou cometer outro crime durante o período que estiver na prisão. 
O tempo total de cada período é normalizado para $h$, assim, o tempo gasto trabalhando é $h-I_{t}-k_{t}$. Indivíduos podem ganhar $\omega_{t} H_{t}+\epsilon_{t}$ por unidade de tempo gasto trabalhando, onde $\omega_{t}$ representa o salário ou preço do capital humano, $H_{t}$, é o nível de habilidade do indivíduo e $\epsilon_{t}$ são possíveis choques no mercado de trabalho com média zero, independentes e identicamente distribuídos (iid). O tempo gasto cometendo crime gera um retorno líquido $N$ dado por:

$$
N_{t}=f_{l}\left[k_{t}, H_{t}, \theta, \eta_{t}\right]
$$

onde $\theta$ é a habilidade para o crime e $\eta_{t}$ são possíveis choques nos retornos da atividade criminal com média zero e iid. Estes retornos são não decrescentes em $H_{t}$ e estritamente crescentes e côncavos em $k_{t}$ e $\theta . H_{t}$, por sua vez, é dado por:

$$
H_{t}=H_{t-1}+f_{2}\left[I_{t-1}, H_{t-1} ; A\right]
$$

onde $A$, é a capacidade de aprendizagem do indivíduo e $f_{2}($.) é crescente e côncava em todos os seus argumentos.

Indivíduos com maior $A$ obtém maior retorno no investimento em capital humano, ou seja, $\frac{\partial^{2} f_{2}}{\partial A \partial I}>0$. Logo, $A$ tem influência sobre a criminalidade, pois indivíduos mais habilidosos, normalmente, investem mais tempo para acumular competências e obtém maior retorno por unidade de tempo investido em capital humano, o que também aumenta os retornos no mercado de trabalho. Pelos mesmos motivos, indivíduos que iniciam a atividade produtiva com maior nível de capital humano $\left(H_{0}\right)$, tenderão a cometer menos crimes. Além disso, $A$ e $H_{0}$ elevados, alteram o custo da prisão, pois o encarceramento representa a renúncia de oportunidades de aprendizado e no mercado de trabalho.

Sendo assim, fatores que refletem elevados $A$ e $H_{0}$ ou baixo $\theta$ devem ser negativamente correlacionados com o crime. Estes gostos e habilidades são quase certamente, conforme o autor, moldados pela família, escola e vizinhança nas idades iniciais do ciclo de vida do indivíduo. Logo, intervenções precoces na atividade educacional podem ajudar a compensar os déficits de aprendizagem ou alterar o gosto para o crime, o que pode reduzir substancialmente a posterior participação na atividade criminosa.

Deming (2011) analisou o efeito da qualidade da escola sobre o crime, com informações de escolas americanas nos anos de 2008 e 2009, e observou que a redução na criminalidade se dá, em grande parte, anos após a matrícula na escola. Cano-Urbina e Lochner (2016) estimaram que o aumento da escolaridade média das mulheres norte americanas reduz as taxas de prisão por crimes violentos e de propriedade, porém não foi observada essa relação nos crimes de colarinho branco. Embora o efeito seja pequeno, os autores observaram ainda que a qualidade da escola (medida pela razão aluno-professor, duração do período e salários dos professores) pode ter efeito sobre o encarceramento e as prisões de mulheres. 
Heckman et al. (2013) evidenciaram que o programa Perry, realizado durante a pré-escola, foi capaz de reduzir o posterior engajamento dos participantes em atividades criminosas nos Estados Unidos. Utilizando informações de crianças em escolas públicas na Carolina do Norte, Cook e Kang (2016) obtiveram evidências significativas de que a evasão escolar está relacionada ao envolvimento criminal e que as crianças nascidas logo após a data de corte para a matrícula em creches públicas são mais propensas a abandonar a escola e a cometer um delito aos 19 anos de idade.

Machin et al. (2011) observaram que a mudança lei que aumentou a idade mínima de frequência escolar obrigatória na Inglaterra e no País de Gales no início da década de 1970 gerou diminuições significativas nos crimes contra a propriedade. No mesmo sentido, Hjalmarsson et al. (2015) analisaram a reforma da escolaridade obrigatória na Suécia e observaram que um ano adicional de escolaridade diminui a probabilidade de condenação em $6,7 \%$ e a de encarceramento em 15,5\%. Anderson (2014) analisou a relação entre a idade mínima de evasão escolar (school dropout) e as taxas de detenção juvenil, explorando a variação nas leis estaduais dos Estados Unidos no período de 1980 a 2008. As evidências sugerem que a idade mínima permitida para a evasão escolar têm um efeito significativo e negativo sobre a taxas de detenção de crimes violentos e contra a propriedade para indivíduos de 16 a 18 anos. Bell et al. (2015) também observaram uma relação entre as leis de escolaridade compulsória e o crime nos grupos de jovens com menores níveis de educação. Dessa forma, através de diferentes medidas, são muitas as evidências de que a educação pode contribuir para reduzir o crime.

Além das medidas de educação, outras variáveis são incluídas nas especificações para a estimação empírica do modelo econômico do crime. No modelo teórico de Becker (1968), para tomar a decisão de execução de um crime, o indivíduo leva em consideração a probabilidade de ser flagrado, condenado e punido. Dessa forma, os gastos com segurança pública são, geralmente, utilizados como uma medida dessa probabilidade. Porém, muitos estudos na literatura nacional não encontraram evidências da relação entre esses gastos e o crime, como Kume (2004), Santos e Kassouf (2007) e Santos (2009), o que levanta a hipótese de que talvez os gastos públicos estejam ineficientemente alocados.

Fajnzlber e Araújo Jr. (2001) utilizaram como medida de segurança pública a taxa de contingente policial militar 100 mil por habitantes e encontraram uma relação negativa com a taxa de homicídios. Em um sentido contrário, é possível ainda que os recursos gastos em segurança pública elevem a eficiência do serviço e, assim, aumentem a probabilidade de registro das atividades criminosas. Resende e Viegas (2011) construíram um indicador para a qualidade da segurança pública, levando em consideração as condições de trabalho, a capacidade e a motivação dos funcionários e observaram que a qualidade da segurança pública reduz os crimes contra a pessoa, mas aparentemente aumenta os crimes contra a propriedade. Bohn et al. (2015) 
encontraram evidências de que a qualidade da educação estaria relacionada com a eficiência dos gastos com segurança pública nos municípios de Minas Gerais.

Outra variável normalmente incluída nas especificações empíricas do modelo econômico do crime é a taxa de desemprego. Um dos canais pelos quais essa taxa pode afetar a criminalidade está relacionado aos retornos esperados do crime, uma vez que a melhora nas condições econômicas e a diminuição da taxa de desemprego aumentam o número de vítimas economicamente atrativas (Fajnzylber; Araújo Jr., 2001; Phillips; Land, 2012).

Cantor e Land (1985) evidenciaram outros dois canais, denominados de efeito da atividade econômica (motivação) e efeito proteção. O primeiro está relacionado ao custo de oportunidade do crime, uma vez que a deterioração das condições econômicas e a incapacidade de o mercado de trabalho absorver a população economicamente ativa aumentam os incentivos para os indivíduos realizarem atividades ilícitas. Já o efeito proteção está relacionado ao fato de o desemprego afetar a frequência e o tempo que o indivíduo permanece no domicílio, protegendo a propriedade e a si mesmo, pois, ao diminuir os deslocamentos entre a casa e o trabalho, diminui a vulnerabilidade e a exposição à vitimização.

Andersen (2012) acrescenta ainda que os efeitos proteção e da atividade econômica podem ocorrer em períodos diferentes. O efeito proteção tem uma relação contemporânea com o crime porque, uma vez que o indivíduo é demitido, ele estará imediatamente no domicílio, guardando a propriedade e protegendo-se da violência das ruas. Já o efeito da atividade econômica pode apresentar uma relação defasada com o crime porque é de se esperar que as pessoas não cometam ações ilícitas para auferir renda no período imediatamente após a demissão. Utilizando informações do censo de Vancouver nos anos de 1991, 1996 e 2001, o autor observou que os efeitos do desemprego sobre o crime no longo prazo são, na maioria das vezes, o dobro dos efeitos de curto prazo. Dessa forma, conforme Fallahi et al. (2012), não é somente o fato de perder o emprego que pode afetar a decisão individual de cometer crimes, mas principalmente a permanência nessa situação de desempregado.

No Brasil, a maioria dos estudos empíricos considera apenas a relação contemporânea entre o crime e o desemprego. Utilizando dados dos estados brasileiros entre 1981 e 1995, Sachsida et al. (2010) observaram uma relação positiva entre o desemprego e a taxa de homicídios. Scorzafave e Soares (2009) observaram uma relação positiva entre o desemprego e a taxa de crimes contra o patrimônio, utilizando informações dos municípios do Estado de São Paulo.

A literatura teórica estabelece que, quanto maior a facilidade de planejar e executar um crime e, portanto, menor o custo, maior o incentivo para engajar na atividade criminosa. Aglomerados urbanos facilitam a troca de informação, a organização, a fuga e dificultam a identificação do criminoso. Nesse sentido, muitos estudos da literatura nacional obtiveram evidências significativas da relação entre a 
taxa de urbanização e o crime, como Araújo Júnior e Fajnzylber (2001), Mendonça (2002), Santos e Kassouf (2007) e Santos (2009), Sachsida et al. (2010).

A renda familiar per capita é, normalmente, utilizada como uma medida do retorno esperado da atividade criminosa e, dessa forma, quanto maior a renda das famílias, maior o retorno. Porém, é possível que esta variável esteja associada aos custos de oportunidade do crime, de modo que, quanto maior a renda, maior o custo de despender um tempo na prisão, no caso do insucesso. A maioria dos estudos da literatura nacional estimaram um efeito líquido positivo, indicando que, pelo menos no caso de crimes letais, o primeiro efeito domina o segundo (Santos, 2009).

As medidas de desigualdade de renda são introduzidas nas especificações empíricas do modelo econômico do crime por confrontar o retorno esperado do crime, associado às potenciais vítimas com alta renda, com o baixo custo de oportunidade, associado aos potenciais criminosos com baixa renda. Outros canais podem estar relacionados a relação entre a concentração de renda e o crime, como a sensação de frustração dos indivíduos de baixa renda em relação a prosperidade dos demais ou a possibilidade de a desigualdade interferir nos mecanismos informais de controle do comportamento dos indivíduos (Fajnzylber; Araújo Jr., 2001; Mendonça, 2002; Santos, 2009).

Scorzafave e Soares (2009) observaram uma relação positiva e significativa entre o índice de Gini e a taxa de crimes contra o patrimônio, utilizando informações dos municípios do Estado de São Paulo. Neste mesmo sentido, utilizando dados de alguns municípios brasileiros, Resende e Viegas (2011) mostraram evidências de que a desigualdade de renda é um fator determinante de crimes orientados para a transferência de propriedade, como furtos e roubos de carros e cargas. Dessa forma, é possível que a desigualdade de renda esteja relacionada com crimes cuja motivação é financeira, uma vez que muitos dos estudos empíricos na literatura nacional não observaram relação significativa entre a desigualdade de renda e a taxa de homicídios (Andrade; Lisboa 2000; Araújo Jr.; Fajnzylber 2001; Fajnzylber; Araújo Jr., 2001; Kume, 2004; Oliveira, 2005; Mendonça, 2002; Santos; Kassouf 2007; Resende; Viegas, 2011; Santos, 2009; Sachsida et al. 2010).

A literatura internacional apresenta algumas evidências de que medidas de desorganização social ou instabilidade familiar pode ter relação com o crime. Case e Katz (1991) observaram que variáveis de estrutura familiar estão significativamente relacionadas com as variáveis de comportamento dos jovens, como por exemplo, a variável para ambos os pais presentes até os 14 anos está negativamente relacionada com a probabilidade de o indivíduo cometer uma atividade ilegal em anos posteriores. Neste mesmo sentido, Levitt e Lochner (2000) observaram uma correlação negativa entre a estrutura familiar (intact family) e a criminalidade. No Brasil, a medida de desorganização social normalmente utilizada é a proporção de lares uniparentais femininos, embora a maioria desses estudos não obtiveram relações significativas dessa variável com o crime, como Fajnzlber e 
Araújo Jr. (2001) e Santos (2009). Resende e Viegas (2011) observaram que o percentual de famílias sem a figura do pai contribui para lesões, estupros e tentativas de homicídio, mas não encontraram significância para os homicídios.

\section{Metodologia}

Um painel de dados dos 26 estados brasileiros e o Distrito Federal é construído entre os anos de 2001 a 2009, compondo uma amostra de 243 observações. Conforme Santos e Kassouf (2007) a estrutura de dados em painel é a melhor estratégia para lidar com os problemas das estimativas de equações da oferta de crimes, que geralmente apresentam heterogeneidade não observável entre as unidades individuais, no caso os Estados. A forma de lidarmos com a heterogeneidade é admitirmos que as características não observáveis dos estados sejam relativamente estáveis no tempo.

Esses efeitos não observados estão relacionados às características culturais que influenciam de forma diferenciada as taxas de crimes nos Estados, como por exemplo, a predisposição a resolver conflitos interpessoais de forma violenta, o consumo de drogas e álcool, a presença de atividades ilegais particularmente lucrativas, a existência de conflitos associados à posse da terra, etc. A presença de efeitos fixos não observáveis é confirmada pelo teste Chow, representado no Apêndice 1.

É necessário considerar também a possibilidade da presença do "efeito inércia" nas taxas de mortes por homicídios que se dá em função da aprendizagem e especialização na atividade criminosa ao longo do tempo, ocasionando a transferência do crime de um período para outro. A literatura nacional apresenta evidências deste efeito (KUME, 2004; SANTOS, 2009). Nesse caso, utiliza-se uma especificação dinâmica através do seguinte modelo em notação matricial:

$$
y_{i t}=y_{i t-1} \gamma+x_{i t}^{\prime} \beta+z_{i}^{\prime} \alpha+\varepsilon_{i t} \quad \text { com }|\gamma|<1
$$

em que $y_{i t}$ é a oferta de crimes da $i$-ésima unidade da federação $(i=1, \ldots, 27)$ no ano $t(t=2001, \ldots, 2009), x_{i t}$ são os regressores, $z_{i}$ é o efeito individual para cada unidade da federação, contendo um termo constante e um conjunto de variáveis específicas de cada estado, e $\mathcal{E}$ é o erro aleatório.

As estimativas consistentes dos parâmetros do modelo dinâmico, onde regressores defasados são introduzidos, podem ser obtidas através do estimador System GMM (GMM-SYS), proposto por Arellano e Bover (1995) e Blundell e Bond (1998), com o uso apropriado das defasagens como instrumentos. No caso de modelos utilizando amostras finitas, a estimação consistente é obtida através do estimador GMM-SYS de 2 estágios com erros padrão robustos, corrigidos da heterocedasticidade (Windmeijer, 2005). 
Para avaliar o ajuste do modelo e a consistência das estimativas, foram utilizados o teste de correlação serial, para observar se os erros em primeira diferença são correlacionados em primeira ordem e não autocorrelacionados em segunda ordem, e o teste de Sargan (test of overidentifying restrictions) para observar a validade conjunta dos instrumentos.

\subsection{Modelo empírico}

Na especificação do modelo empírico, a variável dependente é a taxa de homicídios por agressão por cem mil habitantes, utilizada como medida para a oferta de crimes nos estados brasileiros. A justificativa teórica para o efeito inércia nas taxas de crimes letais é que existe uma aprendizagem e especialização na atividade criminosa ao longo do tempo. Além disso, a sensação de impunidade, decorrente da baixa probabilidade de punição e condenação, contribui para elevar o retorno esperado na atividade criminosa. Fajnzylber e Araújo Jr. (2001) e Santos (2009) apresentam uma ampla discussão teórica e evidências empíricas da presença deste efeito nas estatísticas criminais.

Conforme descrito na introdução e na seção 1, a literatura teórica estabelece vários canais pelos quais a educação pode contribuir para reduzir as taxas de crime. $\mathrm{O}$ ideal de igualdade de acesso somado ao elevado benefício social proporcionado pela educação torna o investimento público na área de extrema importância e uma potencial política de longo prazo de combate à criminalidade. Neste estudo, a medida utilizada é os gastos com educação, que representa os gastos públicos em educação e cultura por habitante ( $\mathrm{R} \$ /$ hab.), a fim de observar o impacto da atuação pública na área da educação sobre o crime.

Conforme, Lochner e Moretti (2009), ao manter os indivíduos ocupados e fora das ruas, o acesso à educação pode reduzir o engajamento em atividades criminosas. Além disso, é plausível esperar que os efeitos de tais gastos sejam observados no médio e longo prazo, pois precisam de um período para serem absorvidos pela população uma vez que, com base nos modelos teóricos, a educação de um indivíduo é resultado de um processo de acúmulo de capital humano que ocorre ao longo do ciclo de vida (Lochner, 2004; Cunha et al., 2006). Por isso, além da relação contemporânea, foi utilizada uma defasagem para esta variável, de modo que é definida como um regressor predeterminado ${ }^{2}$.

Também foram selecionadas algumas variáveis de controle. A primeira delas é a variável gastos com segurança pública, que é a relação dos recursos gastos por habitante ( $\mathrm{R} \$$ hab.), utilizada com a suposição de que, quanto maiores forem os gastos com segurança pública, maior será a eficiência das atividades preventivas e de combate ao crime.

(2) Os regressores predeterminados são correlacionados com os erros passados, mas são não correlacionados com os erros no presente e no futuro. 
Devido à causalidade reversa entre as taxas de crime e os gastos com segurança pública, esta variável é considerada potencialmente endógena ${ }^{3}$ (Loureiro; Carvalho Jr., 2007; Santos, 2009). É possível ainda que, assim como os gastos com educação, os gastos com segurança pública levem algum tempo para serem observados e absorvidos pela população, de modo que o efeito destes gastos sobre a criminalidade seja observado no médio e longo prazo. Por isso, além da relação contemporânea, foi incluída uma defasagem para esta variável.

A variável taxa de desemprego corresponde ao percentual das pessoas que procuraram, mas não encontraram ocupação profissional remunerada entre todas aquelas consideradas ativas no mercado de trabalho. A literatura aponta que a relação entre a taxa de desemprego e a taxa de crime pode ser tanto positiva como negativa. A relação negativa está associada ao retorno esperado do crime, já que, quanto menor a taxa de desemprego, maior o número de vítimas economicamente atrativas. A relação positiva está associada aos custos de oportunidade do crime, já que a incapacidade de o mercado de trabalho absorver a população economicamente ativa pode aumentar os incentivos para os indivíduos envolverem-se em atividades criminosas (Fajnzylber; Araújo Jr., 2001; Phillips; Land, 2012).

Porém, nesse último caso, é possível que a relação não seja imediata, uma vez que é de se esperar que o efeito do desemprego sobre a "motivação" para cometer um crime não ocorra logo após a demissão (Andersen, 2012; Fallahi et al., 2012). Por isso, além da relação contemporânea, foi utilizada uma defasagem para essa variável, de modo que é definida como um regressor predeterminado, assim como os gastos com educação.

A variável urbanização é a razão entre a população urbana e a população total. Em aglomerados urbanos é mais fácil a troca de informação e a organização da atividade criminosa, além da facilidade na fuga e a difícil identificação do criminoso (Glaeser et al. 1992; 1996).

A relação da variável renda familiar per capita (RFPC) com as taxas de crime pode ser tanto positiva como negativa. A relação positiva refere-se aos ganhos do crime, pois quanto maior a renda das famílias, maior o retorno esperado na atividade criminosa. Já a relação negativa está associada aos custos de oportunidade do crime, pois quanto maior a renda maior o custo de despender um tempo na prisão, no caso do insucesso da atividade (Sjoquist, 1973).

A especificação também contém a variável Índice de Gini, que é uma medida de desigualdade na distribuição da renda familiar per capita. Essa variável é normalmente utilizada no modelo econômico do crime como uma medida para a diferença entre o retorno esperado do crime, associado às potenciais vítimas com alta renda, e o baixo custo de oportunidade, associado aos potenciais criminosos com baixa renda. Sendo assim, espera-se uma relação positiva entre a desigualdade de

(3) Os regressores endógenos são contemporaneamente correlacionados com o erro. 
renda e o crime, uma vez que, nos estados com elevada concentração de renda, seriam defrontados as potenciais vítimas e os potenciais criminosos.

Porém, Braithwaite (1979) destaca que, em geral, as áreas de baixa renda têm maiores taxas de crime, o que pode estar relacionado à distribuição dos serviços de segurança. Fajnzylber e Araújo Jr. (2001) argumentam que esse fato não necessariamente invalida as previsões do modelo econômico, uma vez que as teorias sociológicas também preveem uma associação positiva entre crime e desigualdade. Conforme Mendonça (2002), o padrão de consumo imposto pela sociedade pode gerar a insatisfação daqueles que enfrentam restrições orçamentárias. Dessa forma, a "privação relativa" ou a sensação de frustração dos indivíduos de baixa renda em relação a prosperidade dos demais poderiam explicar o efeito da desigualdade sobre o crime.

Além disso, conforme Fajnzylber e Araújo Jr. (2001), a desigualdade pode ter efeito sobre o custo moral se debilitar os mecanismos informais de controle do comportamento dos indivíduos de baixa renda, como as regras de civilidade, moralidade e convivência social, normalmente proporcionadas pela família e pela escola.

A variável lares uniparentais femininos (LUF) é o percentual de famílias chefiadas por mulheres e é incluída nos modelos empíricos do crime como uma medida de desorganização social ou instabilidade familiar (Andrade; Lisboa, 2000; Fajnzylber; Araújo Jr., 2001; Araújo Jr.; Fajnzylber, 2001; Santos; Kassouf, 2007; Santos, 2009).

Foram também utilizados controles para a tendência linear e binárias de tempo.

\subsection{Dados}

A taxa de homicídios, a taxa de urbanização e as estimativas populacionais utilizadas na normalização das taxas de crimes, dos gastos com educação e com segurança pública são fornecidas pelo banco de dados do Sistema Único de Saúde (Datasus).

Os gastos com educação e segurança pública são fornecidos pela Secretaria do Tesouro Nacional e deflacionados para preços de 2009, utilizando como deflator o Índice Nacional de Preços ao Consumidor - INPC, fornecido pelo Instituto de Pesquisa Econômica Aplicada (IPEAdata). A variável taxa de desemprego também é disponibilizada pelo IPEAdata.

A renda familiar per capita e o Índice de Gini são construídos a partir dos dados da Pesquisa Nacional por Amostras de Domicílios (PNAD) e deflacionadas utilizando o deflator dos dados da PNAD disponível no IPEAdata. O percentual de lares uniparentais femininos é construído a partir dos dados da variável tipo de 
família da PNAD, considerando as famílias formadas por mães com filhos em qualquer idade ${ }^{4}$.

A amostra é composta por 243 observações dos 26 estados brasileiros e o Distrito Federal, observados entre os anos de 2001 a 2009. As estatísticas descritivas das variáveis selecionadas para compor o modelo do crime estão na Tabela 1. A variação em torno da média é chamada de variação overall e pode ser decomposta entre a variação através do tempo para um único estado (variação within) e a variação entre os estados (variação between).

Tabela 1

Estatísticas descritivas das variáveis do modelo do crime - Brasil, 2001-2009

\begin{tabular}{|c|c|c|c|c|c|}
\hline Variável & Dimensão & Média & $\begin{array}{l}\text { Desvio } \\
\text { Padrão }\end{array}$ & Mínimo & Máximo \\
\hline \multirow{3}{*}{$\begin{array}{l}\text { Crime } \\
\text { (por cem mil habitantes) }\end{array}$} & overall & \multirow{3}{*}{27,44} & 12,12 & 8,40 & 60,30 \\
\hline & between & & 11,24 & 11,04 & 52,46 \\
\hline & within & & 4,98 & 11,54 & 43,57 \\
\hline \multirow{3}{*}{$\begin{array}{l}\text { Gastos com educação } \\
\text { (Reais de 2009/habitante) }\end{array}$} & overall & \multirow{3}{*}{218,59} & 189,48 & 24,36 & 1061,76 \\
\hline & between & & 116,70 & 98,73 & 511,75 \\
\hline & within & & 150,78 & $-149,04$ & 854,14 \\
\hline \multirow{3}{*}{$\begin{array}{l}\text { Gastos com segurança } \\
\text { pública } \\
\text { (Reais de 2009/habitante) }\end{array}$} & overall & \multirow{3}{*}{104,97} & 85,16 & 0,52 & 402,77 \\
\hline & between & & 42,87 & 43,41 & 183,61 \\
\hline & within & & 74,00 & $-59,25$ & 326,52 \\
\hline \multirow{3}{*}{ Desemprego } & overall & \multirow{3}{*}{9,28} & 2,62 & 4,49 & 20,54 \\
\hline & between & & 2,23 & 5,10 & 14,60 \\
\hline & within & & 1,44 & 1,35 & 15,63 \\
\hline \multirow{3}{*}{ Urbanização (\%) } & overall & \multirow{3}{*}{80,07} & 8,76 & 62,50 & 96,70 \\
\hline & between & & 8,74 & 66,78 & 96,46 \\
\hline & within & & 1,68 & 73,33 & 86,43 \\
\hline \multirow{3}{*}{$\begin{array}{l}\text { Renda familiar per capita } \\
\text { (Reais de 2009) }\end{array}$} & overall & \multirow{3}{*}{487,56} & 194,41 & 221,81 & 1323,95 \\
\hline & between & & 186,46 & 266,68 & 1091,42 \\
\hline & within & & 64,62 & 315,84 & 720,10 \\
\hline \multirow{3}{*}{ Índice de Gini } & overall & \multirow{3}{*}{0,56} & 0,04 & 0,45 & 0,64 \\
\hline & between & & 0,03 & 0,47 & 0,62 \\
\hline & within & & 0,02 & 0,48 & 0,63 \\
\hline \multirow{3}{*}{$\begin{array}{l}\text { Lares uniparentais } \\
\text { femininos }\end{array}$} & overall & \multirow{3}{*}{0,18} & 0,02 & 0,12 & 0,24 \\
\hline & between & & 0,02 & 0,13 & 0,21 \\
\hline & within & & 0,01 & 0,12 & 0,23 \\
\hline
\end{tabular}

Fonte: Elaboração do autor.

(4) Não foram consideradas as informações da área rural da antiga região norte (Rondônia, Acre, Amazonas, Roraima, Pará, Amapá) nos dados da PNAD, uma vez que não estão disponíveis nos anos de 2001, 2002 e 2003. Já os dados do Datasus apresentam estas informações, pois se baseiam em projeções intercensitárias. 


\section{Resultados}

Os resultados das estimações do modelo de painel dinâmico para observar o efeito dos gastos com educação sobre o crime nos estados brasileiros estão representados na Tabela 2. As estimativas foram realizadas com base em informações dos 26 estados e o Distrito Federal, nos anos de 2001 a 2009. A estrutura de dados em painel é empregada como forma de controlar a heterogeneidade não observável dos Estados, já que características culturais, sociais e políticas, consideradas estáveis no tempo, podem influenciar as taxas de crimes.

A especificação dinâmica do modelo de criminalidade permite controlar a presença do possível "efeito inércia" do crime, através da inclusão da taxa de homicídios defasada do lado direito da equação. Para as variáveis gastos com educação, gastos com segurança pública e taxa de desemprego, além da relação contemporânea, foi incluída uma defasagem para observar os efeitos de longo prazo dessas variáveis sobre a criminalidade, considerando que esses gastos podem levar certo tempo para serem observados e absorvidos pela população, assim como o efeito do desemprego sobre a decisão de ingresso no crime pode não ser imediato.

Devido à dupla causalidade entre as taxas de crime e os gastos com segurança pública, essa variável é considerada como potencialmente endógena, de modo que é correlacionada com os erros no presente e no passado. Já as variáveis gastos com educação e taxa de desemprego são consideradas predeterminadas por aparecerem tanto contemporaneamente como com uma defasagem, o que as torna correlacionadas com os erros no passado. Por isso, foram utilizados instrumentos na estimação dessas variáveis, assim como na estimação do efeito inércia $\left(\mathrm{Crime}_{t-1}\right)$. As demais variáveis são consideradas exógenas.

No modelo [a] todas as defasagens são utilizadas como instrumentos. Já o modelo [b] considera a possibilidade de a introdução de binárias de tempo e o erro de medida na variável dependente invalidar os instrumentos em $t-2$ para as equações em primeira diferença e $t-1$ para as equações em níveis, conforme evidenciado por Kume (2004) e, nesse caso, o procedimento adotado é utilizar como instrumentos defasagens a partir de $t-3$ para as equações em primeira diferença e $t-2$ para as equações em níveis. Observamos pouca variação comparando os dois modelos em termos de significância e magnitude das estimativas dos parâmetros, talvez em decorrência de utilizarmos como variável dependente a taxa de homicídios, que é menos sujeita ao sub-registro, em função de ser registrado um boletim no instituto médico legal e na polícia quando há perda da vida humana.

Também foram obtidas estimativas dos parâmetros do modelo excluindose as observações do Distrito Federal para analisar se a discrepância da renda familiar per capita (RFPC) em relação aos demais estados pode interferir nos resultados. Conforme as informações do Apêndice 2, a RFPC do Distrito Federal é 49\% maior 
do que a de São Paulo, que tem a segunda maior RFPC. Os resultados estão representados nas colunas 5 a 8 da Tabela 2 e, de maneira geral, também observamos pouca variação entre os modelos em termos de significância e magnitude dos parâmetros

As estimativas foram realizadas controlando a tendência linear juntamente com as binárias de tempo (colunas 1, 2, 5 e 6) e também foram estimadas equações controlando apenas a tendência linear (colunas 3, 4, 7 e 8). Além disso, foram realizadas estimativas controlando apenas as binárias de tempo, sem o controle da tendência linear, e os resultados estão disponíveis no Apêndice 3.

\section{Tabela 2}

Resultados das estimações para o modelo de painel dinâmico da taxa de homicídios dos estados brasileiros, 2001-2009

\begin{tabular}{|c|c|c|c|c|c|c|c|c|}
\hline & \multicolumn{4}{|c|}{ Com o Distrito Federal } & \multicolumn{4}{|c|}{ Sem o Distrito Federal } \\
\hline & Modelo a & Modelo b & Modelo a & Modelo b & Modelo a & Modelo b & Modelo a & Modelo b \\
\hline & (1) & (2) & (3) & (4) & (5) & (6) & (7) & (8) \\
\hline \multirow{2}{*}{$\log \left(\right.$ Crime $\left._{t-1}\right)$} & $0,857 * * *$ & $0,841 * * *$ & $0,864 * * *$ & $0,842 * * *$ & 0,871 *** & $0,865^{* * * *}$ & $0,876 * * *$ & $0,849^{* * *}$ \\
\hline & $(0,045)$ & $(0,052)$ & $(0,052)$ & $(0,072)$ & $(0,046)$ & $(0,055)$ & $(0,054)$ & $(0,073)$ \\
\hline \multirow{2}{*}{ Log(G. Educ.) } & $-0,011$ & 0,040 & $-0,025$ & 0,001 & $-0,013$ & 0,021 & $-0,023$ & $-0,010$ \\
\hline & $(0,036)$ & $(0,059)$ & $(0,037)$ & $(0,060)$ & $(0,032)$ & $(0,060)$ & $(0,040)$ & $(0,063)$ \\
\hline \multirow{2}{*}{$t-1$} & $-0,073^{*}$ & $-0,125^{*}$ & $-0,046^{*}$ & $-0,033^{*}$ & $-0,094 * *$ & $-0,116^{*}$ & $-0,045^{*}$ & $-0,044^{*}$ \\
\hline & $(0,038)$ & $(0,066)$ & $(0,025)$ & $(0,019)$ & $(0,038)$ & $(0,062)$ & $(0,026)$ & $(0,025)$ \\
\hline \multirow{2}{*}{ Log(G. Seg.) } & $-0,036$ & $-0,045$ & 0,022 & 0,013 & $-0,054 * *$ & $-0,078^{*}$ & 0,013 & 0,020 \\
\hline & $(0,023)$ & $(0,031)$ & $(0,036)$ & $(0,050)$ & $(0,025)$ & $(0,041)$ & $(0,039)$ & $(0,061)$ \\
\hline \multirow{2}{*}{$t-1$} & 0,025 & $-0,001$ & 0,015 & $-0,011$ & 0,011 & $-0,025$ & 0,010 & $-0,001$ \\
\hline & $(0,028)$ & $(0,026)$ & $(0,024)$ & $(0,034)$ & $(0,026)$ & $(0,032)$ & $(0,024)$ & $(0,039)$ \\
\hline \multirow{2}{*}{ Log(Desemp.) } & 0,073 & 0,059 & 0,047 & 0,012 & 0,097 & 0,075 & 0,056 & 0,019 \\
\hline & $(0,067)$ & $(0,081)$ & $(0,080)$ & $(0,093)$ & $(0,062)$ & $(0,082)$ & $(0,074)$ & $(0,089)$ \\
\hline \multirow{2}{*}{$t-1$} & $0,174 * * *$ & $0,256^{* * *}$ & $0,136^{* *}$ & $0,150 * *$ & $0,205^{* * *}$ & $0,312^{* * * *}$ & $0,157 * * *$ & $0,176^{* *}$ \\
\hline & $(0,038)$ & $(0,066)$ & $(0,058)$ & $(0,069)$ & $(0,035)$ & $(0,070)$ & $(0,057)$ & $(0,069)$ \\
\hline \multirow{2}{*}{ Log(Urban.) } & $0,785^{*}$ & $1,214 * *$ & $1,533^{* * * *}$ & $1,710^{* *}$ & $1,045^{* *}$ & $1,524 * *$ & $1,692 * * *$ & $1,839^{* * *}$ \\
\hline & $(0,421)$ & $(0,550)$ & $(0,549)$ & $(0,682)$ & $(0,439)$ & $(0,606)$ & $(0,565)$ & $(0,676)$ \\
\hline \multirow{2}{*}{$\log ($ RFPC) } & 0,065 & 0,145 & $0,326^{* * *}$ & $0,326 * *$ & 0,181 & $0,295 *$ & $0,372 * * *$ & $0,350 * *$ \\
\hline & $(0,099)$ & $(0,145)$ & $(0,107)$ & $(0,155)$ & $(0,122)$ & $(0,177)$ & $(0,114)$ & $(0,170)$ \\
\hline \multirow{2}{*}{$\log ($ Gini) } & 0,294 & 0,686 & $0,768^{* *}$ & $1,199 * * *$ & 0,391 & $0,781 *$ & $0,833^{* *}$ & $1,226^{* * *}$ \\
\hline & $(0,355)$ & $(0,435)$ & $(0,320)$ & $(0,428)$ & $(0,332)$ & $(0,436)$ & $(0,330)$ & $(0,414)$ \\
\hline
\end{tabular}


Tabela 2 - Continuação

\begin{tabular}{|c|c|c|c|c|c|c|c|c|}
\hline & \multicolumn{4}{|c|}{ Com o Distrito Federal } & \multicolumn{4}{|c|}{ Sem o Distrito Federal } \\
\hline & Modelo a & Modelo b & Modelo a & Modelo b & Modelo a & Modelo b & Modelo a & Modelo b \\
\hline & (1) & (2) & (3) & (4) & (5) & (6) & (7) & (8) \\
\hline \multirow{2}{*}{$\log (\mathrm{LUF})$} & 0,005 & 0,097 & 0,174 & $0,339 *$ & 0,059 & 0,161 & $0,215^{*}$ & $0,346^{*}$ \\
\hline & $(0,111)$ & $(0,175)$ & $(0,117)$ & $(0,185)$ & $(0,125)$ & $(0,215)$ & $(0,113)$ & $(0,203)$ \\
\hline \multirow{2}{*}{ Ano } & $0,002^{* * * *}$ & $0,002 * * *$ & $0,002 * * *$ & $0,003^{* * * *}$ & $0,002 * * *$ & $0,003 * * *$ & $0,003 * * *$ & $0,003^{* * *}$ \\
\hline & $(0,001)$ & $(0,001)$ & $(0,001)$ & $(0,001)$ & $(0,001)$ & $(0,001)$ & $(0,001)$ & $(0,001)$ \\
\hline \multirow{2}{*}{2004} & $-0,063^{*}$ & $-0,065$ & & & $-0,040$ & $-0,033$ & & \\
\hline & $(0,033)$ & $(0,040)$ & & & $(0,035)$ & $(0,040)$ & & \\
\hline \multirow{2}{*}{2005} & 0,063 & 0,094 & & & $0,114 * *$ & $0,155^{* * *}$ & & \\
\hline & $(0,045)$ & $(0,061)$ & & & $(0,044)$ & $(0,059)$ & & \\
\hline \multirow{2}{*}{2006} & $0,136^{* *}$ & 0,144 & & & $0,197 * * *$ & $0,227 * *$ & & \\
\hline & $(0,066)$ & $(0,088)$ & & & $(0,070)$ & $(0,090)$ & & \\
\hline \multirow{2}{*}{2007} & 0,079 & $0,173^{*}$ & & & $0,153 * *$ & $0,241 * *$ & & \\
\hline & $(0,063)$ & $(0,093)$ & & & $(0,067)$ & $(0,099)$ & & \\
\hline \multirow[b]{2}{*}{2008} & $0,153^{* *}$ & $0,197 * *$ & & & $0,208^{* * * *}$ & $0,253^{* * *}$ & & \\
\hline & $(0,062)$ & $(0,089)$ & & & $(0,065)$ & $(0,091)$ & & \\
\hline \multirow{2}{*}{2009} & $0,173 * *$ & $0,202 * *$ & & & $0,223^{* * * *}$ & $0,274 * * *$ & & \\
\hline & $(0,070)$ & $(0,096)$ & & & $(0,077)$ & $(0,101)$ & & \\
\hline $\mathrm{N}^{\circ}$ de obs. & 243 & 243 & 243 & 243 & 234 & 234 & 234 & 234 \\
\hline Defasagens & 2 a 8 & 3 a 8 & 2 a 8 & 3 a 8 & 2 a 8 & 3 a 8 & 2 a 8 & 3 a 8 \\
\hline \multicolumn{9}{|c|}{ Testes (p-valor) } \\
\hline Sargan & 0,5836 & 0,8418 & 0,0271 & 0,0842 & 0,6719 & 0,9353 & 0,0249 & 0,0706 \\
\hline \multicolumn{9}{|c|}{ Correlação serial } \\
\hline $\operatorname{AR}(1)$ & 0,0027 & 0,0058 & 0,0017 & 0,0041 & 0,0027 & 0,0053 & 0,0018 & 0,0043 \\
\hline $\mathrm{AR}(2)$ & 0,3719 & 0,4788 & 0,5341 & 0,6924 & 0,1792 & 0,2153 & 0,3438 & 0,5636 \\
\hline
\end{tabular}

Notas: *,** e $* * *$ denotam, respectivamente, significância de $10 \%, 5 \%$ e 1\%; Estimativas obtidas através do método GMM-SYS em dois estágios; Erro-padrão robusto entre parênteses;

Os testes de Sargan e de correlação serial foram empregados para verificar a validade da especificação dinâmica do modelo onde, além do "efeito inércia" do crime, introduzimos defasagens nos regressores, tornando necessário o uso de instrumentos para identificar as variáveis endógenas e predeterminadas. O teste de Sargan verifica a hipótese nula de que a correlação entre os erros e os instrumentos é zero. Dessa forma, a falha em rejeitar a hipótese nula indica que os instrumentos são robustos nas especificações que incluem o controle da tendência linear e as binárias de tempo, colunas $1,2,5$ e 6 . Já o teste de correlação serial verifica a hipótese de que os erros são serialmente não correlacionados. Os resultados mostram 
que os erros em primeira diferença são correlacionados em primeira ordem e não correlacionados em segunda ordem, indicando que os instrumentos utilizados não são correlacionados com o termo do erro.

O resultado da estimação da inércia criminal ficou entre 0,84 e 0,87 , dependendo da especificação do modelo, confirmando a hipótese da transferência do crime de um período para outro, através da aprendizagem e especialização na atividade criminosa ao longo do tempo.

Conforme Santos (2009), o coeficiente estimado da taxa de homicídios defasada $(\hat{\gamma})$ permite obter uma estimativa do tempo necessário para que um choque em uma variável explicativa se dissipe totalmente no sistema, através da relação $\gamma^{t^{*}}=\tau$, onde $\tau$ é o caminho até o eventual equilíbrio em resposta ao choque no tempo $t^{*}$. Se, por exemplo, considerarmos $\tau=0,5$, ou seja, a metade do caminho, a medida do grau de persistência de possíveis choques nas variáveis explicativas será dada por $t^{*}=\ln (0,5) / \ln (\hat{\gamma})$. Assim, estima-se que um eventual choque nas variáveis explicativas demorará em torno de 4 a 5 anos para se dissipar totalmente no sistema.

Além disso, é possível calcular as elasticidades de longo prazo $\left(\hat{\beta}_{l p}\right)$ das variáveis explicativas, através da equação $\hat{\beta}_{l p}=\hat{\beta}_{c p} /(1-\hat{\gamma})$, onde $\hat{\beta}_{c p}$ são as estimativas dos parâmetros estimados dessas variáveis. Fazendo isso, estima-se que as elasticidades de longo prazo sejam maiores que as de curto prazo em, aproximadamente, 643,1\%. Esse resultado refere-se a estimativa do modelo da coluna 6, que não considera as informações do Distrito Federal, utiliza 3 a 8 defasagens dos instrumentos e inclui controle da tendência linear e as binárias de tempo. A interpretação dos resultados das variáveis explicativas será baseada nos resultados dessa especificação.

A primeira defasagem da variável gastos com educação mostrou-se negativa e significativa, com elasticidade de aproximadamente 0,116 . Porém, não foi observada relação contemporânea desta variável com o crime. Esses resultados são evidências em favor da hipótese de que os gastos públicos em educação podem contribuir para reduzir o crime, embora o efeito seja somente observado com um período de defasagem. Isso já era esperado, dado que tais gastos precisam de pelo menos um período para que sejam absorvidos pela população.

Embora a variável analisada seja gastos totais com educação, é importante destacar que os recursos devem estar eficientemente alocados para melhorar a qualidade e para aumentar a educação formal da população, uma vez que, conforme o modelo econômico do crime, o canal pelo qual a educação contribui para reduzir a criminalidade é que um indivíduo mais educado tem melhores oportunidades no 
mercado de trabalho e considera mais custoso dispender tempo na prisão no caso de uma punição (Becker, 1968).

Os resultados encontrados também podem ser uma evidência em favor da hipótese do modelo teórico desenvolvido por Lochner (2004) de que as intervenções na atividade educacional alteram o gosto para o crime, o que pode reduzir substancialmente a posterior participação na atividade criminosa. Seguindo essa ideia, considerando que a escolaridade afeta diretamente as noções de moralidade e civilidade e os custos psíquicos de desobedecer às leis, é provável que um indivíduo educado torne-se mais paciente e mais avesso ao risco de cometer um crime, e não utilize o aprendizado e a experiência em atividades ilegais (Becker; Mulligan, 1997; Arrow, 1997).

Porém, o que temos são evidências de que isso pode estar acontecendo, pois para fazer afirmações precisas nesse sentido, no caso do Brasil, precisaríamos de dados mais completos, com informações individuais. Mesmo assim, os resultados encontrados apontam que intervenções na atividade educacional podem ajudar a reduzir a atividade criminosa e somam-se a literatura empírica que observa um efeito líquido negativo na relação entre as medidas de educação e o crime.

A relação contemporânea entre a taxa de homicídios e os gastos com segurança pública foi significativa apenas nas especificações dos modelos representados nas colunas 5 e 6 da Tabela 2, indicando que, por exemplo, um aumento de $10 \%$ nos gastos dos estados leva a uma redução de $7,8 \%$ na taxa de homicídios, resultado da coluna 6 . Não foram observadas relações significativas na defasagem dos gastos. Conforme a literatura relacionada, a dificuldade em encontrar relações significativas pode ser devido a possibilidade de os gastos públicos em segurança estarem ineficientemente alocados (Kume, 2004; Santos; Kassouf, 2007; Santos, 2009).

Já os parâmetros estimados da variável taxa de desemprego com uma defasagem foram significativos em todas as especificações. No caso do modelo da coluna 6, a elasticidade estimada é 0,312. Este resultado está de acordo com a hipótese de que o desemprego afeta os custos de oportunidade do crime, porém a relação não é imediata uma vez que o efeito do desemprego sobre a decisão de participar de atividades ilícitas não ocorre logo após a demissão (Andersen, 2012; Fallahi et al., 2012). Não foi observada relação contemporânea entre o desemprego e o crime. Essa relação, conforme a literatura econômica, estaria relacionada ao maior número de potenciais vítimas no caso de uma diminuição da taxa de desemprego.

A variável urbanização apresentou uma relação positiva e significativa com a taxa de homicídios em todas as estimações. Com base nos resultados do 
modelo da coluna 6, a elasticidade estimada foi de, aproximadamente, 1,52 no curto prazo e 11,33 no longo prazo.

As estimativas das variáveis da renda familiar per capita (RFPC) e do índice de Gini foram positivas e significativas no modelo da coluna $6^{5}$. O resultado estimado da elasticidade de curto prazo da RFPC é 0,295, indicando que o possível efeito econômico da renda sobre o crime associado ao maior retorno esperado da atividade criminosa supera o efeito associado aos custos de oportunidade. $\mathrm{O}$ valor calculado para a elasticidade de longo prazo é 2,19.

No caso do índice de Gini, a elasticidade estimada é 0,78 no curto prazo e 5,8 no longo prazo. Assim, por exemplo, um aumento de $10 \%$ no Índice de Gini, com as demais condições constantes, pode aumentar a taxa de homicídios em 7,8\% no curto prazo e $58 \%$ no longo prazo. Esse resultado está de acordo com a teoria econômica do crime, que postula que uma elevada concentração da renda nos estados pode aumentar a taxa de homicídios por defrontar indivíduos com baixa renda e, portanto, com baixo custo de oportunidade de ingressar no crime, com indivíduos de alta renda, que representam um alto retorno da atividade criminosa.

As ciências sociais preveem outros canais para explicar essa relação, como a insatisfação e a frustração dos indivíduos de baixa renda frente as privações relativas de consumo (Mendonça, 2002). Além disso, a desigualdade pode afetar os mecanismos informais de controle do comportamento, como as noções de moralidade e civilidade e as regras de convivência social, normalmente proporcionadas pela família e pela escola e, assim, interferir no "custo moral" dos indivíduos de baixa renda (Fajnzylber; Araújo Jr., 2001).

Os parâmetros estimados da variável lares uniparentais femininos (LUF) não foram significativos nas especificações com instrumentos válidos. Isso pode ser devido à pouca variabilidade das observações nos anos analisados ${ }^{6}$ ou talvez essa não seja uma boa medida para desorganização social e instabilidade familiar no caso do Brasil, onde as leis relacionadas ao divórcio avançam no sentido de garantir o envolvimento financeiro e emocional de ambos os pais na criação dos filhos.

O parâmetro estimado da variável ano, utilizada como controle da tendência linear, foi positivo e significativo em todas as especificações, com valores entre 0,002 e 0,003. As binárias de tempo que foram significativas também apresentaram um sinal positivo, com exceção apenas do ano de 2004 na especificação do modelo representado na coluna 1 da Tabela 2.

(5) Como os resultados do teste Sargan indicaram a invalidade dos instrumentos nas especificações dos modelos usando apenas o controle da tendência linear, sem as binárias de tempo, as estimativas dos parâmetros das colunas 3, 4, 7 e 8 não serão interpretados.

(6) Apêndice 2 


\section{Conclusões}

Com os resultados deste estudo, buscou-se avançar no debate da identificação das variáveis que afetam o crime e na elaboração de políticas públicas que contribuam para reduzir a criminalidade, através da mensuração da relação entre a atuação pública na área de educação e o crime, utilizando como medida os gastos públicos em educação e cultura. Para isso, foram utilizados dados socioeconômicos dos estados brasileiros e um modelo dinâmico (GMM-SYS) com uma defasagem para os gastos com educação, além da relação contemporânea, pois é necessário um período para que esses gastos possam ser absorvidos pela população.

Observamos uma elasticidade negativa de aproximadamente 0,1 na primeira defasagem, ou seja, se os gastos com educação aumentarem 10\%, a taxa de crime diminui $1 \%$ no período seguinte, indicando que gastos públicos em educação podem contribuir para reduzir o crime, porém é necessário um período para que o efeito seja observado. Conforme o modelo econômico do crime, o principal canal pelo qual a educação contribui para reduzir a criminalidade é que um indivíduo mais educado tem melhores oportunidades no mercado de trabalho e considera mais custoso dispender tempo na prisão, no caso de uma punição. O resultado encontrado também pode ser uma evidência de que as intervenções na atividade educacional alteram o gosto para o crime e afetam diretamente as noções de moralidade e civilidade e os custos psíquicos de desobedecer às leis, o que pode reduzir substancialmente a posterior participação na atividade criminosa.

A hipótese da transferência do crime de um período para outro foi confirmada pela estimativa do efeito inércia da atividade criminal. As variáveis de controle também evidenciaram alguns resultados importantes, por exemplo, um aumento de $10 \%$ nos gastos com segurança pública dos estados pode levar a uma redução de 7,8\% na taxa de homicídios. A elasticidade estimada da taxa de desemprego com uma defasagem foi 0,312 , o que é uma evidência de que o efeito do desemprego sobre a decisão de participar de atividades ilícitas não ocorre de forma imediata. A elasticidade estimada da variável urbanização foi 1,52 no curto prazo e 11,33 no longo prazo. Já a renda familiar per capita apresentou elasticidade de 0,295 no curto prazo e 2,19 no longo prazo. No caso do índice de Gini, um aumento de $10 \%$, com as demais condições constantes, pode aumentar a taxa de homicídios em 7,8\% no curto prazo e $58 \%$ no longo prazo.

Esse estudo é um primeiro passo para indicar empiricamente que a atuação pública na área de educação pode ser uma política de longo prazo para a redução da criminalidade. Um segundo passo seria identificar as formas mais eficientes de alocar os recursos para orientar a elaboração das políticas. Outro possível avanço para esse estudo seria inserir controles espaciais para analisar também as questões 
geográficas que influenciam a criminalidade. Neste estudo, admitimos a ausência de qualquer tipo de correlação espacial entre os estados, uma vez que a possibilidade de dependência espacial é pequena e talvez ocorra apenas nas áreas de fronteira. A abordagem considerando questões espaciais é comum em trabalhos que utilizam informações de municípios ou microrregiões.

\section{Referências bibliográficas}

ALMEIDA, E. S.; HADDAD, E. A.; HEWINGS, G. J. D. The spatial pattern of crime in Minas Gerais: an exploratory analysis. Economia Aplicada, Ribeirão Preto, v. 9, n. 1, p.39-55, 2005.

ANDERSEN, A. M. Unemployment and crime: a neighborhood level panel data approach. Social Science Research, v. 41, n. 6, p. 1615-1628, Nov. 2012.

ANDERSON, D. M. In school and out of trouble? The minimum dropout age and juvenile crime. Review of Economics and Statistics, v. 96, p. 318-331, 2014.

ANDRADE, M. V.; LISBOA, M. B. Desesperança de vida: homicídio em Minas Gerais, Rio de Janeiro e São Paulo no período 1981/97. In: HENRIQUES, R. (Ed.). Desigualdade e pobreza no Brasil. Rio de Janeiro: Ipea, 2000. p. 347-384.

ARAÚJO JÚNIOR, A.; FAJNZYLBER, P. O que causa a criminalidade violenta no Brasil? Uma análise a partir do modelo econômico do crime: 1981 a 1996. Belo Horizonte: Universidade Federal de Minas Gerais, Cedeplar, 2001. 50p. (Texto de Discussão, n. 162).

ARELLANO, M.; BOND, S. Some tests of specification for panel data: Monte Carlo evidence and application to employment equations. Review of Economic Studies, Oxford, v. 58, p. 277-297, 1991.

ARELLANO, M.; BOVER, O. Another look at the instrumental variable estimation of error-components models. Journal of Econometrics, Amsterdam, v. 68, p. 29-51, 1995.

ARROW, K. The benefits of education and the formation of preferences. In: BEHRMAN, J.; STACEY, N. (Ed.). The social benefits of education. Ann Arbor, MI: University of Michigan Press, 1997. p. 11-16.

BECKER, G. S. Crime and punishment: an economic approach. The Journal of Political Economy, Chicago, v. 76, n. 2, p. 169-217, 1968.

BECKER, G. S.; MULLIGAN, C. B. The endogenous determination of time preference. Quarterly Journal of Economics, Oxford, v. 112, n. 3, p. 729-758, Aug. 1997.

BELLA, B; COSTA, R; MACHIN, S. Crime, compulsory schooling laws and education. Economics of Education Review, v. 54, p. 214-226, Oct. 2016. 
BLUNDELL, R.; BOND, S. Initial conditions and moment restrictions in dynamic panel data models. Journal of Econometrics, Amsterdam, v. 87, p. 115-143, 1998.

BOHN, L.; DALBERTO, C. R.; ERVILHA, G. T.; GOMES, A. P. Os determinantes da eficiência dos gastos públicos com segurança nos municípios mineiros: uma análise a partir da metodologia DEA. Economic Analysis of Law Review, v. 6, n. 1, 2015.

BRAITHWAITE, J. Inequality, crime, and public policy. London and Boston: Routledge and Kegan Paul, 1979.

CANO-URBINA, J.; LOCHNER, L. The effect of education and school quality on female crime. Centre for Human Capital and Productivity. London, ON: Department of Economics, University of Western Ontario, 2016. (CHCP Working Papers, n. 2016-3).

CANTOR, D.; LAND, K. Unemployment and crime rates in the post World War II United States: a theoretical and empirical analysis. American Sociological Review, v. 50, p. 317-332, 1985.

CARNEIRO, F. G.; LOREIRO, P. R. A.; SACHSIDA, A. Crime and social interactions: a developing country case study. The Journal of Socio-Economics, Amsterdã, v. 34, p. 311-318, 2005.

CARVALHO, A. X.; CERQUEIRA, D. R. C.; RODRIGUES, R. I.; LOBÃO, W. J. A. Custos das mortes por causas externas no Brasil. Brasília: Ipea, 2007. p. 1-42. (Texto de Discussão, n. 1268).

CASE, A.; KATZ, L. The company you keep: the effects of family and neighborhood on disadvantaged youths. Cambridge: National Bureau of Economic Research, 1991. (NBER Working Paper, n. 3705).

CERQUEIRA, D; SOARES, R. The welfare cost of homicides in Brazil: accounting for heterogeneity in the willingness to pay for mortality reductions. Health Economics, v. 25, p. 259-276, 2016.

CHIODA, L.; MELLO, J. M. P.; SOARES, R. Spillovers from conditional cash transfer programs: Bolsa Família and crime in urban Brazil. Economics of Education Review, v. 54, p. 306-320, 2015.

COOK, P. J.; KANG, S. Birthdays, schooling, and crime: regression-discontinuity analysis of school performance, delinquency, dropout, and crime initiation. American Economic Journal: Applied Economics, v. 8, n. 1, p. 33-57, 2016.

CUNHA, F.; HECKMAN, J.; LOCHNER, L.; MASTEROV, D. Interpreting the evidence on life cycle skill formation. Handbook of the Economics of Education, v. 1, p. 697-812, 2006. 
DEMING, D. Better schools, less crime? Quarterly Journal of Economics, v. 126, p. 2063-2115, 2011.

FAJNZYLBER, P.; ARAÚJO JÚNIOR, A. Violência e criminalidade. In: LISBOA, M. B. MENEZES FILHO, N. A. (Ed.). Microeconomia e sociedade no Brasil. Rio de Janeiro: Contracapa Editora, 2001. p. 333-394.

FALLAHI, F.; POURTAGHI, H.; RODRÍGUEZ, G. The unemployment rate, unemployment volatility, and crime. International Journal of Social Economics, v. 39, n. 6, p. 440-448, 2012.

GLAESER, E. L.; SACERDOTE, B.; SCHEINKMNA, J. A. Crime and social interactions. Quarterly Journal of Economics, Oxford, v. 111, n. 2, p. 507-548, 1995.

GLAESER, E. L.; KALLAL, H. D.; SCHEINKMAN, J. A.; SHLEIFER, A. Growth in cities. Journal of Political Economy, Chicago, v. 100, n. 6, p. 1126-1152, 1992.

HECKMAN, J; PINTO, R.; SAVELYEV. P. Understanding the mechanisms through which an influential early childhood program boosted adult outcomes. American Economic Review, v. 103, n. 6, p. 2052-2086, 2013.

HJALMARSSON, R.; HOLMLUND, H.; LINDQUIST, M. J. The effect of education on criminal convictions and incarceration: causal evidence from microdata. Economic Journal, n. 125, n. 587, p. 1290-1326, 2015.

KLING, J. The effect of prison sentence length on the subsequent employment and earnings of criminal defendants. Princeton: Princeton University, 2002. p. 1-41. (Working Paper).

KUME, L. Uma estimativa dos determinantes da taxa de criminalidade brasileira: uma aplicação em painel dinâmico. In: ENCONTRO NACIONAL DE ECONOMIA, 32., 2004. João Pessoa. Anais... João Pessoa: Anpec, 2004. p. 1-16.

LEVITT, S. D.; LOCHNER L. The determinants of juvenile crime. Chicago: University of Chicago Press, 2000. p. 1156-1185.

LOCHNER, L. Education, work, and crime: A human capital approach. Cambridge: National Bureau of Economic Research, 2004. p. 1-43. (NBER Working Paper, n. 10478).

LOCHNER, L. Non-production benefits of education: crime, health, and good citizenship. Centre for Human Capital and Productivity. London, ON: Department of Economics, University of Western Ontario, 2010. (CHCP Working Papers, n. 2010-7)

LOCHNER, L. Education policy and crime. In COOK, P.; LUDWIG, J.; MCCRARY, J. (Ed.). Controlling crime: strategies and tradeoffs. Chicago: University of Chicago Press, 2011. p. 465-515. 
LOCHNER, L.; MORETTI, E. The effect of education on crime: evidence from prison inmates, arrests, and self-reports. The American Economic Review, Pittsburgh, v. 94, n. 1, p. 155-189, Mar. 2004.

MACHIN, S.; MARIE, O.; VUJIC, S. The crime reducing effect of education. Economic Journal, v. 121, n. 552, p. 463-484, 2011.

MENDONÇA, M. J. C. Criminalidade e violência no Brasil: uma abordagem teórica e empírica. Revista Brasileira de Economia de Empresas, Brasília, v. 2, n. 1, p. 3349, 2002.

OLIVEIRA, C. A. Criminalidade e o tamanho das cidades brasileiras: Um enfoque da economia do crime. In: ENCONTRO NACIONAL DE ECONOMIA, 33., 2005. Natal. Anais... Natal: Anpec, 2005. p.1-23.

PHILLIPS, J.; LAND, K. The link between unemployment and crime rate fluctuations: an analysis at the county, state, and national levels. Social Science Research, v. 41, n. 3, p. 681-694, May 2012.

RESENDE, J. P.; VIEGAS, M. Crime social, Castigo social: desigualdade de renda e taxas de criminalidade nos grandes municípios brasileiros. Estudos Econômicos, São Paulo, v. 41, n. 1, p. 173-195, jan./mar. 2011.

SACHSIDA, A.; MENDONÇA, M. J. C.; LOUREIRO, P. R. A; GUTIERREZ, M. B. S. Inequality and criminality revisited: further evidence from Brazil. Empirical Economics, v. 39, n. 1, p. 93-109, 2010.

SANTOS, M. J. Dinâmica temporal da criminalidade: mais evidências sobre o efeito inércia nas taxas de crimes letais nos estados brasileiros. Economia, Brasília, Anpec, v. 10, n. 1, p. 170-194, 2009.

SANTOS, M. J.; KASSOUF, A. L. Estudos econômicos da criminalidade no Brasil: evidências e controvérsias. Economia, Brasília, Anpec, v. 9, p. 343-372, 2008.

SANTOS, M. J.; KASSOUF, A. L. Uma investigação econômica da influência do mercado de drogas ilícitas sobre a criminalidade brasileira. Economia, Brasília, Anpec, v. 8, n. 2, p. 187-210, 2007.

SCORZAFAVE, L. G.; SOARES, M. K. Income inequality and pecuniary crimes. Economics Letters, Amsterdã, v. 104, p. 40-42, 2009.

SOARES, R. R. Development, crime, and punishment: accounting for the international differences in crime rates. Journal of Development Economics, Amsterdã, v. 73, p. 155-184, 2004.

SJOQUIST, D. L. Property crime and economic behavior: some empirical results. The American Economic Review, Pittsburgh, v. 63, n. 3, p. 439-446, 1973.

WINDMEIJER, F. A finite sample correction for the variance of linear efficient twostep GMM estimators. Journal of Econometrics, Amsterdã, v. 126, p. 25-51, 2005. 


\section{Apêndice 1}

Teste Chow para a presença de efeitos fixos - Brasil 2001-2009

\begin{tabular}{|c|c|c|}
\hline & Com DF & Sem DF \\
\hline \multirow{2}{*}{ Log(G. Educ.) } & $-0,011$ & $-0,020$ \\
\hline & $(0,072)$ & $(0,077)$ \\
\hline \multirow{2}{*}{ Log(G. Seg.) } & $-0,031$ & $-0,032$ \\
\hline & $(0,025)$ & $(0,028)$ \\
\hline \multirow{2}{*}{ Log(Desemp.) } & 0,015 & 0,016 \\
\hline & $(0,079)$ & $(0,080)$ \\
\hline \multirow{2}{*}{ Log(Urban.) } & $6,878 * * *$ & $6,833 * * *$ \\
\hline & $(0,897)$ & $(0,928)$ \\
\hline \multirow{2}{*}{$\log ($ RFPC $)$} & $0,816^{* * *}$ & $0,837 * * *$ \\
\hline & $(0,221)$ & $(0,226)$ \\
\hline \multirow{2}{*}{$\log ($ Gini $)$} & $-0,026$ & $-0,075$ \\
\hline & $(0,396)$ & $(0,408)$ \\
\hline \multirow{2}{*}{$\log ($ LUF $)$} & 0,070 & 0,071 \\
\hline & $(0,158)$ & $(0,163)$ \\
\hline \multirow{2}{*}{ Ano } & $-0,002$ & $-0,002$ \\
\hline & $(0,050)$ & $(0,052)$ \\
\hline \multirow{2}{*}{2004} & 0,052 & 0,053 \\
\hline & $(0,092)$ & $(0,097)$ \\
\hline \multirow{2}{*}{2005} & $-0,067$ & $-0,061$ \\
\hline & $(0,164)$ & $(0,175)$ \\
\hline \multirow{2}{*}{2006} & $-0,125$ & $-0,113$ \\
\hline & $(0,226)$ & $(0,241)$ \\
\hline \multirow{2}{*}{2007} & $-0,167$ & $-0,149$ \\
\hline & $(0,311)$ & $(0,332)$ \\
\hline \multirow{2}{*}{2008} & $-0,279$ & $-0,269$ \\
\hline & $(0,333)$ & $(0,353)$ \\
\hline \multirow{2}{*}{2009} & $-0,283$ & $-0,276$ \\
\hline & $(0,380)$ & $(0,400)$ \\
\hline $\mathrm{N}^{\circ}$ de obs. & 243 & 234 \\
\hline Teste Chow & 62,88 & 52,93 \\
\hline$(p$-valor $)$ & 0,00 & 0,00 \\
\hline
\end{tabular}

Notas: $* * *$ e $* * *$ denotam, respectivamente, significância de $10 \%, 5 \%$ e 1\%; Erro-padrão entre parênteses; 
Uma análise do efeito dos gastos públicos em educação sobre a criminalidade no Brasil

\section{Apêndice 2}

Médias das variáveis do modelo de criminalidade - por Estado, 2001-2009

\begin{tabular}{|c|c|c|c|c|c|c|c|c|}
\hline Estados & Crime & $\begin{array}{l}\text { Gasto } \\
\text { Educ. }\end{array}$ & $\begin{array}{c}\text { Gasto } \\
\text { Seg. }\end{array}$ & $\begin{array}{c}\text { Desem- } \\
\text { prego }\end{array}$ & Urban. & RFPC & Gini & $\begin{array}{l}\text { L. uni. } \\
\text { fem. }\end{array}$ \\
\hline $\mathrm{AC}$ & 21,10 & 450,71 & 183,61 & 8,20 & 68,47 & 513,18 & 0,60 & 0,21 \\
\hline $\mathrm{AL}$ & 45,20 & 113,65 & 97,30 & 9,83 & 72,67 & 284,24 & 0,60 & 0,19 \\
\hline AP & 32,94 & 477,29 & 178,25 & 14,60 & 91,41 & 413,94 & 0,53 & 0,19 \\
\hline AM & 20,20 & 211,99 & 95,54 & 12,12 & 76,26 & 397,86 & 0,55 & 0,20 \\
\hline $\mathrm{BA}$ & 21,87 & 118,40 & 70,65 & 10,78 & 71,31 & 325,09 & 0,58 & 0,19 \\
\hline $\mathrm{CE}$ & 21,28 & 168,86 & 43,41 & 8,28 & 74,51 & 309,02 & 0,58 & 0,20 \\
\hline DF & 35,09 & 447,25 & 61,16 & 12,80 & 96,06 & $1.110,49$ & 0,62 & 0,21 \\
\hline $\mathrm{ES}$ & 51,46 & 174,42 & 107,92 & 9,17 & 82,12 & 540,83 & 0,55 & 0,17 \\
\hline GO & 25,58 & 177,58 & 95,03 & 8,15 & 90,96 & 530,32 & 0,54 & 0,17 \\
\hline MA & 14,74 & 104,35 & 45,09 & 7,54 & 69,23 & 266,68 & 0,58 & 0,19 \\
\hline MT & 33,59 & 200,03 & 129,29 & 7,44 & 82,08 & 529,36 & 0,54 & 0,14 \\
\hline MS & 30,17 & 201,59 & 140,77 & 8,13 & 86,33 & 561,91 & 0,55 & 0,17 \\
\hline MG & 19,37 & 145,04 & 142,62 & 9,09 & 85,62 & 515,86 & 0,54 & 0,19 \\
\hline PA & 27,10 & 106,71 & 61,47 & 9,38 & 72,67 & 373,46 & 0,54 & 0,20 \\
\hline $\mathrm{PB}$ & 21,72 & 138,30 & 70,85 & 9,04 & 74,91 & 342,70 & 0,60 & 0,19 \\
\hline PR & 28,10 & 223,51 & 62,43 & 7,11 & 85,51 & 633,48 & 0,53 & 0,15 \\
\hline PE & 52,46 & 98,73 & 74,24 & 12,00 & 79,47 & 333,14 & 0,60 & 0,21 \\
\hline PI & 12,08 & 121,25 & 44,94 & 5,62 & 68,19 & 310,77 & 0,60 & 0,19 \\
\hline RJ & 45,18 & 225,74 & 177,85 & 11,43 & 96,46 & 733,50 & 0,56 & 0,19 \\
\hline $\mathrm{RN}$ & 15,98 & 174,63 & 78,92 & 9,82 & 75,46 & 366,57 & 0,58 & 0,19 \\
\hline RS & 19,01 & 169,77 & 94,56 & 7,17 & 84,28 & 670,76 & 0,53 & 0,15 \\
\hline $\mathrm{RO}$ & 36,40 & 220,10 & 166,41 & 8,08 & 66,78 & 506,15 & 0,53 & 0,16 \\
\hline RR & 27,92 & 511,75 & 152,67 & 10,54 & 79,99 & 411,81 & 0,55 & 0,20 \\
\hline $\mathrm{SC}$ & 11,04 & 186,88 & 107,99 & 5,10 & 82,59 & 704,04 & 0,47 & 0,13 \\
\hline SP & 25,67 & 310,04 & 125,99 & 10,77 & 93,72 & 746,05 & 0,53 & 0,17 \\
\hline SE & 27,87 & 183,63 & 101,49 & 11,05 & 73,27 & 362,75 & 0,57 & 0,21 \\
\hline TO & 17,58 & 265,83 & 118,84 & 7,15 & 81,49 & 389,35 & 0,56 & 0,16 \\
\hline
\end{tabular}

Fonte: elaboração do autor, com base nos dados citados na seção 2.2. 


\section{Apêndice 3}

Resultados das estimações para o modelo de painel dinâmico da taxa de homicídios dos estados brasileiros, 2001-2009

\begin{tabular}{|c|c|c|c|c|}
\hline & \multicolumn{2}{|c|}{ Com o DF } & \multicolumn{2}{|c|}{ Sem DF } \\
\hline & Modelo a & Modelo b & Modelo a & Modelo b \\
\hline \multirow[t]{2}{*}{$\log \left(\right.$ Crime $\left._{t-1}\right)$} & $0,831 * * *$ & $0,797 * * *$ & $0,843 * * *$ & $0,820 * * *$ \\
\hline & $(0,041)$ & $(0,044)$ & $(0,039)$ & $(0,039)$ \\
\hline \multirow[t]{2}{*}{ Log(G. Educ.) } & $-0,023$ & 0,046 & $-0,021$ & 0,024 \\
\hline & $(0,036)$ & $(0,053)$ & $(0,031)$ & $(0,045)$ \\
\hline \multirow[t]{2}{*}{$t-1$} & $-0,050$ & $-0,127 * *$ & $-0,070 * *$ & $-0,109 * *$ \\
\hline & $(0,035)$ & $(0,062)$ & $(0,035)$ & $(0,050)$ \\
\hline \multirow[t]{2}{*}{$\log ($ G. Seg. $)$} & $-0,025$ & $-0,015$ & $-0,048^{*}$ & $-0,051$ \\
\hline & $(0,028)$ & $(0,044)$ & $(0,028)$ & $(0,044)$ \\
\hline \multirow[t]{2}{*}{$t-1$} & 0,024 & 0,015 & 0,009 & $-0,010$ \\
\hline & $(0,025)$ & $(0,032)$ & $(0,022)$ & $(0,030)$ \\
\hline \multirow[t]{2}{*}{ Log(Desemp.) } & 0,046 & 0,045 & 0,072 & 0,063 \\
\hline & $(0,065)$ & $(0,077)$ & $(0,057)$ & $(0,070)$ \\
\hline \multirow[t]{2}{*}{$t-1$} & $0,127 * * *$ & $0,170 * * *$ & $0,156 * * *$ & $0,222 * * *$ \\
\hline & $(0,035)$ & $(0,053)$ & $(0,033)$ & $(0,051)$ \\
\hline \multirow[t]{2}{*}{ Log(Urban.) } & $0,286^{*}$ & $0,305^{*}$ & 0,164 & 0,145 \\
\hline & $(0,162)$ & $(0,171)$ & $(0,173)$ & $(0,176)$ \\
\hline \multirow[t]{2}{*}{$\log (\mathrm{RFPC})$} & $0,147^{*}$ & 0,160 & 0,030 & 0,031 \\
\hline & $(0,082)$ & $(0,099)$ & $(0,105)$ & $(0,122)$ \\
\hline \multirow[t]{2}{*}{$\log ($ Gini $)$} & 0,104 & 0,019 & 0,131 & 0,046 \\
\hline & $(0,318)$ & $(0,352)$ & $(0,315)$ & $(0,336)$ \\
\hline \multirow[t]{2}{*}{$\log ($ LUF $)$} & 0,120 & 0,093 & 0,055 & 0,063 \\
\hline & $(0,122)$ & $(0,162)$ & $(0,152)$ & $(0,199)$ \\
\hline \multirow{2}{*}{2004} & $-0,060 * *$ & $-0,065^{*}$ & $-0,035$ & $-0,035$ \\
\hline & $(0,029)$ & $(0,033)$ & $(0,029)$ & $(0,031)$ \\
\hline \multirow{2}{*}{2005} & 0,056 & 0,078 & $0,109 * *$ & $0,135 * * *$ \\
\hline & $(0,043)$ & $(0,052)$ & $(0,043)$ & $(0,050)$ \\
\hline \multirow{2}{*}{2006} & $0,151 * *$ & $0,141^{*}$ & $0,217 * * *$ & $0,225^{* * *} *$ \\
\hline & $(0,061)$ & $(0,075)$ & $(0,063)$ & $(0,077)$ \\
\hline \multirow{2}{*}{2007} & 0,078 & $0,175^{*}$ & $0,156^{* *}$ & $0,235 * *$ \\
\hline & $(0,072)$ & $(0,093)$ & $(0,077)$ & $(0,096)$ \\
\hline \multirow{2}{*}{2008} & $0,168 * * *$ & $0,223 * * *$ & $0,230 * * *$ & $0,277 * * *$ \\
\hline & $(0,060)$ & $(0,074)$ & $(0,061)$ & $(0,075)$ \\
\hline \multirow{2}{*}{2009} & $0,196 * * *$ & $0,212 * * *$ & $0,251 * * *$ & $0,285^{* * *}$ \\
\hline & $(0,064)$ & $(0,077)$ & $(0,069)$ & $(0,082)$ \\
\hline $\mathrm{N}^{\circ}$ de obs. & 243 & 243 & 234 & 234 \\
\hline Defasagens & 2 a 8 & 3 a 8 & 2 a 8 & 3 a 8 \\
\hline \multicolumn{5}{|l|}{ Testes ( $p$-valor) } \\
\hline Sargan & 0,3640 & 0,3882 & 0,3365 & 0,2644 \\
\hline \multicolumn{5}{|c|}{ Correlação serial } \\
\hline $\mathrm{AR}(1)$ & 0,0028 & 0,0052 & 0,0026 & 0,0053 \\
\hline $\operatorname{AR}(2)$ & 0,4855 & 0,5594 & 0,2260 & 0,2276 \\
\hline
\end{tabular}

Notas: *, ** e *** denotam, respectivamente, significância de 10\%, 5\% e 1\%; Estimativas obtidas através do método GMM-SYS em dois estágios; Erro-padrão robusto entre parênteses. 